\title{
Investigations on Mortality in Grass Carp (Ctenopharyngodon idella) Reared under Captive Farming System
}

\author{
Rakesh Kumar*, Anmol Bisht, Abhishek Kumar and Rajesh Kumar Asrani \\ Department of Veterinary Pathology, DGCN COVAS CSKHPKV, \\ Palampur, Himachal Pradesh-176062, India \\ *Corresponding author
}

\section{A B S T R A C T}

\section{Keywords}

Grass Carp,

Necropsy,

Histopathology,

Stress, Septicemia

Article Info

\section{Accepted:}

12 April 2021

Available Online:

10 May 2021
The present investigation describes an outbreak among captive grass carp fishes reared by a farmer in a pond near Palampur area, Himachal Pradesh. Clinical signs among affected fishes included inactive swimming/lethargy behavior, no food intake and sudden mortality over a period of 3-4 days. Necropsy examination depicted the presence of necrotic lesions with fibrino-hemorrhagic exudate over hepato-pancreas, pin point hemorrhages accompanied with fibrinous exudates in other visceral organs including coelomic wall along with splenomegaly. The histopathological lesions in the liver comprised of severely lost structural details of hepatocytes, sinusoidal congestion with hemorrhages and deposition of eosinophilic fibrinous exudate along with mononuclear cells infiltration (MNCs). Prominent areas of necro-hemorrhagic tracts along with leucocytic infiltrates were also visible in the pancreatic tissue. The gill filaments showed increased vascularity with fibrin deposition on microscopic evaluation. Based on the gross and histopathological findings the present outbreak causing septicemia among grass carp was attributed to the stress factors such as overcrowding, hypoxia as a result of algal bloom, poor sanitation, imbalance in dissolved gaseous combination, and capture or transportation stress.

\section{Introduction}

Aquaculture has become a diversified and demanding source of protein and food over past decades (Akinrotimi et al., 2007). Stress factors determined in successful captive fish farming include over-crowding, hyper or hyposalinity, hypoxia, water pollutants, malnutrition, water $\mathrm{pH}$, photoperiod, hyper or hypothermia, transportation and accumulation of nitrogenous and other metabolic waste products (Gabriel and Akinrotimi, 2011). Stressors of any origin can alter neuroendocrine and immune system of all the vertebrates and mediatethe release of adrenocoticotropic hormone (ACTH) from the pituitary gland (Rehman et al., 2017). Septicaemic conditions of viral and bacterial 
origin are very important for the aquatic animals especially fishes (Sandlund et al., 2014). Hemorrhagic septicemia of viral origin often leads to petechial hemorrhages throughout the internal organs, gills and coelomic body cavity (Olesen and Skall, 2013). Streptococcus iniae, Citrobacter freundii, Klebsiella pneumoniae and Escherichia coli are some of the potential infectious agents responsible to cause heavy mortality in aquatic creatures and also pose threat to human population (Anderson et al., 2018). The blood borne infections cause a significant economic loss to the commercial fish farmers. The septicaemic conditions of viral origin can lead to $100 \%$ mortality in fingerlings and approximately 30-40 \% mortality in adult fishes (Skall et al., 2005; Olesen and Skall, 2013).

\section{Materials and Methods}

A farmer had kept around 800 grass carp fishes in a pond near to Palampur area. In the month of November, 2019 some of the fishes started showing respiratory distress, sluggish and inactive swimming, and refusal of feed. Around 40-50 fishes in the pond died over a period of 3-4 days. One dead fish immediately after death and one live fish showing clinical symptoms were presented for the necropsy examination to the Department of Veterinary Pathology, DGCN COVAS CSKHPKV, Palampur, Himachal Pradesh. The live fish was sacrificed by stunning method and a systemic and thorough examination of both the fishes was done. The macroscopic lesions observed during necropsy examination were recorded and photographed. The $0.5 \mathrm{~cm}$ thick tissue sections of internal organs including hepato-pancreas, kidneys, gills, spleen, heart and intestine showing pathological alterations were collected in $10 \%$ neutral buffered formalin (NBF) solution. The fixed tissue sections were dehydrated in ascending grades of alcohol, cleared in benzene, impregnated with molten paraffin and sectioned to 4-6 micron thickness. The processed tissue sections were stained with Hematoxylin and Eosin $(\mathrm{H} \& \mathrm{E})$ as per the standard protocol (Luna, 1968). As per the history of stagnant water, increased stock density, increased intensity of turbidity and algal bloom the owner was suggested with treatment escorted with the immediate preventive and control measures to the carps stocked.

As per the instructions the farmer has shifted the diseased fishes to the other pond and administrated Oxytetracycline @ $55 \mathrm{mg} / \mathrm{Kg}$ body weight via oral route for 10 days. The overcrowding among carps was reduced by the transportation to the other pond. The greenish algae smeared over the pond were cleared by the owner. The mortality among the fishes was totally declined to the zero level. Dissolved $\mathrm{O}_{2}$ is very important for fishes to undergo metabolic processes in the body.

If water is deficient in $\mathrm{O}_{2}$ as a result of algal bloom, high stocking density or stagnant water, continuous accumulation of $\mathrm{CO}_{2}$ can contribute to inactivate the respiratory apparatus and develop stress among fishes. The diseased fishes in the pond exhibited abnormal behavior in swimming, orientation, decreased activity, refusal of feed and swimming very sluggishly were similar to one of the studies conducted by Parvez and Mudarris (2014). These abnormal changes in behavior of fish may correspond to pathogenic microorganisms as well (Rehman et al., 2017).

\section{Results and Discussion}

External examination of the fishes during necropsy revealed no abnormality around ocular area, fins and abdomen. On internal examination, gills were found be severely congested with slimy appearance(Fig. 1), while liver depicted the presence of miliary whitish coloured necrotic patches along with 
pinpoint hemorrhagic spots and fibrinous exudate. The petechial hemorrhages in association with fibrinous exudation were evident over pancreas and coelomic walls. The intestinal loops also showed the presence of fibrino-hemorrhagic tracts forming adhesions with coelomic wall and other visceral organs(Fig. 2).The spleen in the fishes was enlarged. The necrotic, hemorrhagic and fibrinous exudative lesions in different internal organs in fish might be an indication of septicemic conditions of bacterial or viral origin and parallel studies were concluded by Olesen and Skall (2013).

The histopathological examination of the liver showed disorganization of hepatic tissue, engorged sinusoidal capillaries, areas of coagulative necrosis with fibrinous exudate along with severe inflammatory cells infiltration especially MNCs (Fig. 3\& Fig. 4).

\begin{tabular}{|c|c|c|c|}
\hline $\begin{array}{l}\text { Fig.1 Gills showing diffuse congestion along with } \\
\text { slimy appearnce (arrows) }\end{array}$ & $\begin{array}{l}\text { Fig.2 Visceral organs showing diffuse necro- } \\
\text { hemorrhagic areas along with fibrinous exudates } \\
\text { (arrows) }\end{array}$ \\
\hline Fig.3 Hepato-pancreas exhibiting hydropic \\
degeneartion along with sinusoidal congestion and \\
areas of necrosis. H\&E*100
\end{tabular}




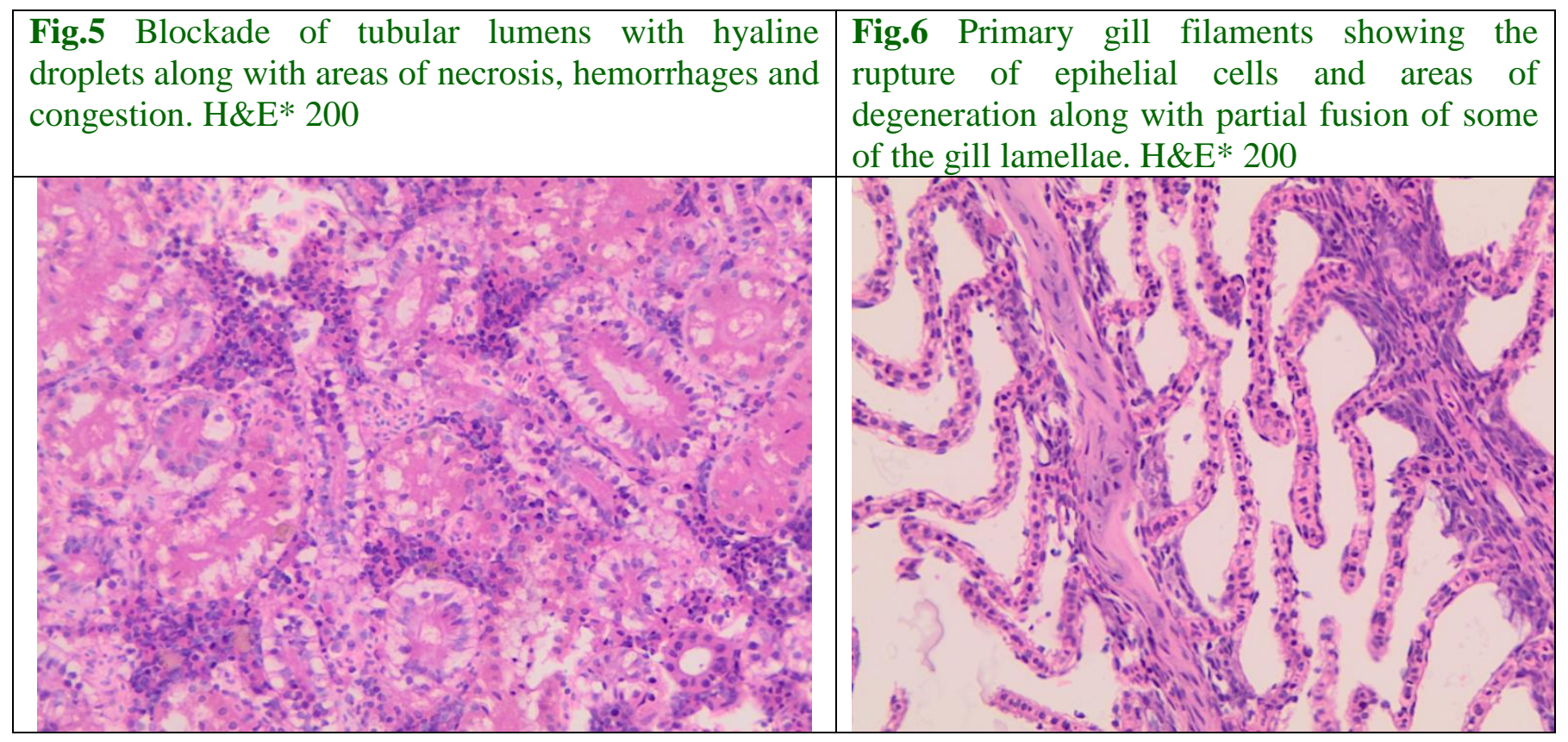

The degenerative changes in renal tubules along with focal areas of hemorrhages, congestion and scattered inflammatory cells were evident (Fig. 5) Microscopic examination of pancreatic tissue also depicted the extensive areas of necrosis, fibrinous exudate, and hemorrhagic patches with leucocytic infiltrates (Skall et al., 2005).

The degenerative changes in gill filaments with increased vascularity were clearly appreciable in the gill sections (Fig. 6) and were in concordance with a study conducted by Flores-Lopes and Thomaz (2011).

The stress factors are the major constraints for sustainable aquaculture and need to be recognized before the start of prominent mortality. Better survival of aquaculture hatchery can be assimilated by refining the water quality, discouraging the overcrowding, timely diagnosis, segregation and treatment of affected stock. This report puts into record the gross and microscopic findings of an outbreak among captive fishes. Although the etiology associated with this septicemic condition among grass carp remains obscured.

\section{Acknowledgment}

Authors are highly grateful to the Dean and Head College of Veterinary and Animal Sciences, CSKHP KV, Palampur for providing necessary support to conduct the research programme.

\section{References}

Akinrotimi, A. O., Gabriel, U. U., Anyanwu, P. E., Anyanwu, A. O., 2007. Influence of sex, Acclimation Methods and Period on Haematology of Sarotherodon Melanotheron (cichilidae). RJBS, 2:348-352.

Anderson, M, T., Mitchell, L. A., Zhao, L. and Mobley, H. L. T, 2018). Citrobacter freundii fitness during bloodstream infection. Sci. Rep8: 11792.

Flores-Lopes, F. and Thomaz, A. T, 2011. Histopathologic alterations observed in fish gills as a tool in environmental monitoring. Braz. J. Biol, 71(1):17988.

Gabriel, U. U, and Akinrotimi, A, 2011. 
Management of Stress in Fish for Sustainable Aquaculture Development. Researcher $3(4)$. http://www.sciencepub.net/researcher

Luna, L. G, 1968. Manual of Histological Staining Methods. Armed Forces Institute of Pathology. New York, NY: McGraw Hill Book Company.

Olesen, N. J and Skall, H. F, 2013. Viral hemorrhagic septicemia virus. In: Munir M, editor. Mononegaviruses of veterinary importance Vol I: Pathobiology and molecular diagnosis: $C A B$ International, 1: 323-336.

Parvez, N. and Mudarris, M. S. A, 2014. Investigation on the Bacterial Hemorrhagic Septicemia Disease of Cyprinuscarpio and Channastriatus. Poul Fish Wildl Sci,2: 116.
doi:10.4172/2375-446X.1000116

Rahman, M. B., Hoque, M. S., Rahman, M. M, and Nahar, A, 2017. Exploration of fishing gear and fisheries diversity of Agunmukha River at Galachipa Upazila in Patuakhali district of Bangladesh. Iran. J. Fish. Sci,16(1):108-126.

Sandlund, N., Gjerset, B., Bergh, O., Modahl, I., Olesen, N. J. and Johansen, R, 2014. Screening for Viral Hemorrhagic Septicemia Virus in Marine Fish along the Norwegian Coastal Line. PLOS One,9(9):e108529.

Skall, H F, Olesen, N. J. and Mellergaard, S, 2005. Viral hemorrhagic septicemia virus in marine fish and its implications for fish farming - a review. J. Fish Dis,28: 509-529.

\section{How to cite this article:}

Rakesh Kumar, Anmol Bisht, Abhishek Kumar and Rajesh Kumar Asrani. 2021. Investigations on Mortality in Grass Carp (Ctenopharyngodon idella) Reared under Captive Farming System. Int.J.Curr.Microbiol.App.Sci. 10(05): 126-131. doi: https://doi.org/10.20546/ijcmas.2021.1005.017 